\title{
Del rojo al azul. Las pantallas de las dos Españas
}

\author{
Josefina MARTínez ${ }^{1}$ \\ Profesora Titular de Historia Compotemporánea (UNED)
}

From Red to Blue. The Screens in «The Two Spains»

\begin{abstract}
RESUMEN
Durante la guerra civil española (1936-

1939) el cine se convirtió en una de las armas principales de la retaguardia. En la zona republicana se optó por la colectivización o la incautación de las salas de exhibición y de las empresas cinematográficas para convertirlas en el elemento clave de la propaganda plural del gobierno, partidos y sindicatos, así como en una fuente de ingresos. Las más de 400 obras producidas pretendían educar y elevar la moral de los españoles a la vez que solicitar al resto del mundo una ayuda que nunca llegó. Entre tanto, en la zona rebelde, con poco más de la cuarta parte de la producción, se creaba un aparato cinematográfico único, bajo las claras consignas censoras de la Falange que, tras el triunfo franquista, dirigirá las líneas de la producción cinematográfica nacional.

\section{PALABRAS CLAVE \\ Cine, guerra civil española, Producción cinematográfica, Exhibición cinematográfica, Anarquismo, Comunismo, Franquismo.
Comatorica, Anarquismo,}

ABSTRACT

Along the Spanish civil war (1936-1939) the cinema became one of the main weapons in the rear. The republican area the theatres and the cinema companies were either collectivized or withheld to turn them into a key element in the government propaganda, political parties and syndicates, as well as an incoming font. The more-than four hundred of titles produced tried to educate and raise the moral of the Spanish while using the films to pledge for the never coming external help. Meanwhile in the rebel area was produced only a quarter of the pieces, but there was created an unique cinematographic machine highly controlled and censored by the Spanish Falangist party which, after the triumph of Franco, would mark the lines of the national cinematographic production.

\section{KEY WORDS \\ Cinema, Movies, Spanish Civil War, cinematographic production, cinematographic exhibition, Anarchy, Comunism, Franquism.}

\footnotetext{
1 La autora agradece muy especialmente la amistad y la ayuda prestada por Enrique Blanco Arroyo, fallecido el 17 de abril de 2009, asi como la de Victoria de Lucio, jefa de la Mediateca de la UNED; José Luis La Torre (AHN), Mercedes Martín Palomino (AGA), Pilar Casado (AMAE), Virginia García de Paredes (ABE), Concha Sanz (AMC), Javier Herrera, director de la Biblioteca de Filmoteca Española, Marga Lobo (FE) y Rafael Areste para la elaboración de este artículo.
}

«A Enrique Blanco Arroyo. In memoriam» 


\section{INTRODUCCIÓN}

Como cada tarde desde 1896, cuando su padre, Eduardo Jimeno Peromarta, decidió instalarse en Madrid, abandonar su exposición ambulante de figuras de cera y abrir un barracón cinematográfico en la plaza de Bilbao, Eduardo Jimeno Correas, aquel sábado 18 de julio de 1936, se acercó caminando a su flamante despacho instalado en el novedoso cine Proyecciones de la calle Fuencarral. Inaugurado el 21 de diciembre de 1932, él lo consideraba «el salón más moderno, agradable y visitado de la capital»².

Jimeno Correas no podía sospechar que unos días después un Consejo Obrero le iba a echar el alto. Su Proyecciones pasaba a ser incautado y administrado por la UGT. Con medio siglo de profesión a sus espaldas, tras haber sido propietario y empresario, a sus 67 años era recolocado como acomodador. Más o menos ocurría igual en las 2.000 salas repartidas por la España republicana.

Esa misma mañana de julio de 1936, en la que un aire africano aplastaría la tierra, Enrique Blanco Pallarés, propietario de Madrid Film, uno de los 125 laboratorios cinematográficos con mayor solera del país, se hallaba en Estoril. Tras haberse reunido en Madrid con sus compañeros de logia - La Unión n ${ }^{\circ}$ 9-, Mariano Benlliure, Joaquín Dicenta y dos periodistas del diario Informaciones entre otros, había salido hacia Portugal requerido por el general Sanjurjo, de quien era amigo personal. El accidente aéreo que segó la vida de quien iba a asumir el mando de la sublevación, también cambió el rumbo existencial de Enrique Blanco.

Tras el entierro del General, Enrique Blanco se encaminó a Burgos, donde se integró en el primer Gabinete de Prensa de la Junta de Defensa Nacional. El 4 de agosto se trasladó a Salamanca, y en la Sección de Cinematografía de Prensa y Propaganda trabajó voluntariamente y sin retribución hasta el final de la guerra. A partir de abril de 1937 Blanco asumió las funciones de consejero y director del Consejo Cinematográfico de Falange. Entre tanto en Madrid, bajo el mando republicano, sus laboratorios fueron confiscados pasando a ser regentados por un comité obrero. Terminada la guerra, en 1942 será acusado de masón y condenado a 12 años de cárcel. Para salvar su vida, huirá a América $^{3}$.

Mientras tanto, en Valencia, aquella tórrida tarde de 1936 Manuel Casanova Llopis y sus hijos, dueños de CIFESA, una multinacional cinematográfica de aque-

2 MARTíNEZ, J.: «El cine Proyecciones de Madrid: las memorias de Eduardo Jimeno». Secuencias, 3, (1995), pp. 9 a 35.

${ }_{3}$ Centro Documental de la Memoria Histórica. Tribunal Especial para la Represión de la Masonería y el Comunismo. Sumario 887-44 contra Enrique Blanco Pallarés por delito de masonería. TERMC, 10122. Sus servicios al Alzamiento se consideraron eximentes en la sentencia dictada que le condenó a la pena de 12 años y un día de prisión menor, la inhabilitación absoluta y perpetua para desempeñar cualquier cargo en el Estado, entidades subvencionadas, empresas concesionarias, gerencias y consejos de administración de empresas privadas así como cargos de confianza, mandos o dirección de las mismas. 
llos tiempos con sedes en Roma, París, Berlín, Buenos Aires y Manila, escondidos pactaban con sus más fieles empleados la «requisa» de las sucursales para salvarlas de posibles pillajes ${ }^{4}$. Pocos días después saldrían en varios coches con destino a París. Las sucursales de Madrid y Valencia quedaban en zona republicana; la de Sevilla, en la de los sublevados.

El más comprometido con la empresa, Vicente Casanova, en 1938 decidió atravesar un país en llamas hasta llegar a Sevilla, donde firmaría con el Gabinete Civil del general Queipo de Llano un acuerdo para realizar películas de propaganda. A partir de entonces, CIFESA rodó aproximadamente el $20 \%$ de las cintas producidas a favor de los insurrectos ${ }^{5}$.

Hasta ese 18 de julio de 1936, la industria cinematográfica española había seguido el modelo capitalista, acorde a las leyes del mercado, las cuales deciden qué se produce, cómo y para quién. La guerra cambió esas normas. A continuación, estas decisiones las tomarían las autoridades políticas: los partidos, los sindicatos, los organismos públicos, los gobiernos... la producción cinematográfica pasó a ser planificada por el Estado, o los Estados.

Tanto los republicanos como los llamados nacionales concedieron al cine un papel relevante en sus políticas. Pero sus dinámicas serán muy diferentes. Mientras que los sublevados fueron construyendo un aparato de comunicación unitaria, donde el cine será un instrumento al servicio de la conquista del Estado, el modelo cinematográfico republicano seguirá derroteros muy diferentes; el cine será considerado el mejor medio para trasmitir consignas y educar, así como una fuente de ingresos y un sector capaz de absorber una porción significativa de mano de obra. Por estos motivos, la mayor parte de los órganos administrativos políticos y sindicales, locales, autonómicos y centrales intentaron dominarlo. Entre todos lograron dilapidar su valor económico y comunicativo hasta minimizar su influencia social así como su capital humano perdido en los frentes, escondido o huido. A lo largo de estas páginas trataremos la evolución de la industria cinematográfica española en ambos bandos durante el conflicto bélico.

\section{1. ¿QUIÉN HACÍA CINE ANTES DE LA GUERRA?}

En cierto modo, durante el verano del 36 , la producción cinematográfica española comenzaba a despegar. La caída de la monarquía, las secuelas de la crisis de 1929 y la revolución tecnológica propiciada por la llegada del cine sonoro, habían trastocado la vida renqueante de estudios y salas de exhibición. En 1934, con la ascensión de la CEDA (Confederación Española de Derechas Autónomas) al po-

${ }^{4}$ FERNÁNDEZ CUENCA, C.: La Guerra de España y el cine. Madrid, Filmoteca Nacional de España, 1976. Vol. I. p. 102.

${ }^{5}$ Sobre CIFESA véase la obra ya clásica de FANÉS, F.: Cifesa, la antorcha de los éxitos. Valencia. Institución Alfonso el Magnánimo, 1981. 
der, una nueva burguesía apostó por el cine. tras encontrar apoyo económico y una política de contención social. Bajo estas circunstancias la iniciativa privada invirtió en la reconversión de los estudios y salas, comercializó patentes de aparatos sonoros e incrementó la importación y producción de películas.

En 1936 existían en España seis estudios adaptados a la tecnología sonora: dos en Barcelona y cuatro en Madrid. El más antiguo, Orphea, se hallaba instalado en uno de los pabellones de la Exposición Universal de 1929 y puesto en marcha en 1932. También en la ciudad condal, el francés Henri Huet -representante de la Gaumont y dueño del cine Fantasio- creó en 1935 los modestos estudios Lepanto, donde se rodaron dos películas de producción propia y cuatro de producción ajena antes de la guerra.

Entre tanto, en Madrid, una campaña de prensa furibunda contra las películas habladas en el castellano de Hollywood - que coparían el mercado ante la desidia de los productores locales-, estimuló en 1932 la creación de los estudios Cinematográfica Española y Americana (CEA). En su Consejo de Administración se sentaban sólidos empresarios, banqueros y la flor y la nata de los dramaturgos y escritores madrileños ${ }^{6}$. Antes de la guerra produjeron tres largometrajes propios y trece ajenos. Otro de los centros era los Estudios Cinema Español SA. (ECE$\mathrm{SA})$ que, al situarse en Aranjuez, resultaba incómodo a la hora de atraer a equipos para los rodajes, por lo que sufrió un lento despegue. Por su parte, Ballesteros Tona Film, había nacido en 1933 como una empresa auxiliar y pequeños estudios - cuyos dueños eran partidarios de Falange-. Por último quedaban los Roptence, surgidos a la sombra de unos modestos talleres de reparación de aparatos. La fortuna de sus dueños provenía de la invención de un proyector portátil - llamado también Roptence- que atrajo a varios accionistas y culminó con la creación de los estudios en 1935. Este año se pondrán en marcha dos más: Cinearte en Madrid y Kinefón en Barcelona. Este último abriría sus puertas en abril de 1936.

Más que seguir el estilo norteamericano de aglutinar todo el proceso industrial de la producción, estos locales servían para que cualquiera de las empresas productoras del país filmaran sus obras con las condiciones técnicas precisas, garantizando una mínima infraestructura y evitando el desplazamiento a estudios extranjeros.

6 Situados en la Ciudad Lineal, fueron inaugurados el 28 de octubre de 1933 por el propio presidente de la República, Niceto Alcalá Zamora. Disponía de seis platós, laboratorio, taller de decorados y hasta piscina. En su Consejo de Administración, presidido por el empresario Rafael Salgado — director de la Cámara de Comercio de Madrid-, entre otros se sentaban el presidente de la Cámara de los Industriales, Casimiro Mahou, y el consejero del Banco Mercantil e Industrial, Florentino Rodríguez, así como el premio Nobel Jacinto Benevente, Serafín y Quintín Álvarez Quintero, Carlos Arniches, Pedro Muñóz Seca, el periodista Juan Ignacio Luca de Tena, el músico Jacinto Guerrero, Eduardo Marquina y Manuel Linares Rivas. Todos ellos ya habían sufrido veleidades cinematográficas durante el periodo mudo. Como director de los estudios figuraba un reconocido autor cinematográfico, Eusebio Fernández Ardavín. Archivo del Ministerio de Comercio (AMC). Caja 5560. 
Por otra parte, en 1936 se había renovado el parque productivo cinematográfico español. La revolución técnica del sonoro unida a un periodo tan convulso y agitado como el republicano, había provocado la práctica desaparición de las empresas del sector. Serán las distribuidoras quienes tomen el relevo a la hora de producir: Saturnino Ulargui (Ufisa), Exclusivas Diana, Exclusivas Ernesto González, y Atlantic Films en Madrid; Selecciones Capitolio en Barcelona, y Procines (Producción Cinematográfica Española Falcó y Compañía) en Valencia. Ello no fue óbice para que mantuviera su producción alguna pequeña sociedad como Star Films, creada por Rosario Pi en Madrid o Lotos Film en Barcelona, propiedad de uno de los pioneros del cine catalán, Baltasar Abadal. También en la ciudad condal se hallaba Ibérica Films, empresa fundada por judíos huidos de la Alemania de Hitler. A pesar de todos estos cambios, será en dos grandes empresas sobre las que se asiente la moderna industria cinematográfica española: la madrileña Filmófono y la valenciana CIFESA (Compañía Industrial Film Española S.A.).

Desgraciadamente a Filmófono no le dio tiempo a desarrollar sus planes de producción. Había sido creada en 1931 por el industrial liberal Ricargo Urgoiti, quien pretendía dar continuidad a una producción popular pero de calidad, con obras como Don Quintín el amargao, La hija de Juan Simón, ¿Quién me quiere a mí? y iCentinela alerta! ${ }^{7}$. Luis Buñuel se hallaba al frente del estable y sólido equipo artístico de la empresa como productor ejecutivo y accionista. Contaba entre sus filas con los directores más creativos del momento: Luis Marquina, Nemesio Sobrevila y José Luis Sáenz de Heredia. Su sugestiva apuesta fue cercenada por la guerra civil, la derrota republicana y el exilio de sus profesionales.

Por su parte CIFESA llegó a convertirse en la mayor empresa cinematográfica de la República. Además de superar a todas en producción al filmar 12 largometrajes y otros tantos cortomentrajes, su calidad hizo de ellos los preferidos del público. Fundada en 1932, su capital inicial ascendía a un millón y medio de pesetas. Capitaneada por Manuel Casanova, y sus hijos Vicente y Luis - afines a Acción Católica-, tras hacer una rápida fortuna con la distribución de filmes alemanes y la española El agua en el suelo de Eusebio Fernández Ardavín, decidieron invertir en producción. Para ello contrataron a Florián Rey, quien filmó La hermana San Sulpicio (1934), constituyendo el inicio de una serie de éxitos basados en comedias y zarzuelas muy del gusto popular. Pronto abrió sucursales en toda España, en las principales capitales de Europa, de América y en Filipinas. En Berlín fundó la marca Hispano Film Producktion, donde se continuó trabajando durante el periodo bélico.

7 Sobre el cine de la República hay una extensísima bibliografía. Respecto a Filmófono destacaremos CELA, J.: La empresa cinematográfica Española Filmófono, 1929-1936. Madrid, Universidad Complutense, 1995. 
Así pues, al inicio de la guerra existían en España diez empresas productoras con una actividad frecuente que, entre 1931 y la primera mitad de 1936, llevaron a la pantalla 57 largometrajes (Tabla 1).

Tabla 1. Producción de películas sonoras entre 1931 y $1936^{8}$

\begin{tabular}{|l|r|r|r|r|r|r|c|}
\hline EMPRESA & 1931 & 1932 & 1933 & 1934 & 1935 & 1936 & TOTAL \\
\hline CIFESA & & & & 1 & 6 & 5 & 12 \\
\hline Orphea & & & & 8 & 1 & & 9 \\
\hline Excl. Diana & 1 & 1 & 1 & 1 & 2 & 1 & 7 \\
\hline Capitolio & & & & 1 & 2 & 3 & 6 \\
\hline Star Film & & 1 & 1 & 1 & 1 & & 4 \\
\hline Filmófono & & & & & 2 & 2 & 4 \\
\hline Procines & & & & 1 & 2 & 1 & 4 \\
\hline Ibérica & & & & 1 & 3 & & 4 \\
\hline CEA & & & & 1 & 1 & 1 & 3 \\
\hline Lepanto & & & & 2 & 2 & & 4 \\
\hline TOTAL & 1 & 2 & 2 & 17 & 22 & 13 & 57 \\
\hline
\end{tabular}

\section{EL CINE REPUBLICANO DURANTE LA GUERRA: DE LA PRODUCCIÓN PRIVADA A LA SOCIALIZACIÓN}

La división de España en dos territorios dominados por bandos irreconciliables, sostenidos por ejércitos enemigos, con concepciones sobre la organización social y la administración del Estado enfrentadas, resultó nefasto para el cine nacional. Además de sufrir la militarización de técnicos y profesionales, la huida de los actores, la falta de electricidad, de maquinaria, de repuestos y de película virgen, desapareció el capital privado y la figura del productor. Este salto cualitativo fue vitoreado en el bando republicano como una liberalización del «patrón» y de la esclavitud de la comercialización. Todas estas razones llevaron a un drástico descenso de la producción comercial. En los tres años del conflicto sólo se filmarían 15 películas de estas características con bastantes pocas ambiciones artísticas, la cuarta parte de la cifra alcanzada en los años inmediatamente anteriores.

8 Para esta tabla se han utilizado fundamentalmente los datos recogidos por RIAMBAU, E. y TORREIRO, C.: Productores en el cine español. Estado, dependencias y mercado. Madrid, Cátedra/Filmoteca Española, 2008. p. 828. 
Al estallar la guerra había once largometrajes en proceso de producción, siete en Barcelona y cuatro en Madrid ${ }^{9}$. Todos acabarían estrenándose a lo largo de la guerra, excepto Nuestra Natacha de Benito Perojo - que nunca se estrenó-, y Carne de fieras que no llegó a concluirse en aquellos años ${ }^{10}$. El 18 de julio había dos equipos rodando películas en la zona ocupada por los franquistas, uno para CIFESA en Córdoba, que filmaba El genio alegre, y el único equipo de la CEA desplazado a Cádiz para impresionar los exteriores de Asilo naval. Todo el material fue confiscado por el ejército franquista y la mayor parte de los profesionales de ambos grupos se incorporaron a los servicios cinematográficos de los rebeldes ${ }^{11}$. A partir de este momento CEA rodó películas financiadas por las fuerzas navarras - los requetés-, la Falange y la Delegación del Estado para Prensa y Propaganda franquista, establecida en Salamanca y dirigida por Millán Astray. Para la Alta Comisaría de España en Marruecos produjo la película más emblemática de la España sublevada: Romancero marroquí (Carlos Velo, 1939) ${ }^{12}$. Los franquistas, en colaboración con los directivos de las principales productoras, utilizaron sus contactos para rodar la propaganda en Lisboa, Berlín o Roma.

Por su parte, las empresas cinematográficas establecidas en la zona republicana fueron colectivizadas y dedicadas a impresionar documentales propagandísticos. La producción quedó atomizada, consecuencia lógica de la política cinematográfica, o falta de la misma, del gobierno republicano. Desde su llegada al poder, los sucesivos gabinetes nunca se habían hecho cargo de dictar una normativa para el sector, que únicamente se regía por las ordenanzas municipales dictadas en los años veinte sobre espectáculos públicos y censura. La del cine era una industria muy conservadora que, además, empleaba a una pequeña fracción de la población activa, unas 40.000 personas ${ }^{13}$. Asuntos de mayor calado acuciaban a los legisladores. Hasta 1933 no se creó el Consejo de la Cinematografía que, apenas iniciada su actividad, desapareció al comienzo de la guerra ${ }^{14}$.

9 En Barcelona se rodaba Diego Corrientes dirigida por Ignacio F. Iquino, La Alhambra de Antonio Graciani, Usted tiene ojos de mujer fatal de Juan Perellada, Nuevos ideales de Salvador Alberich, La miIlona de Antonio Momplet y Hogueras de la noche de Arthur Porchet. En Madrid, La casa de la Troya de Juan Vila Vilamala y Adolfo Aznar, ¡Centinela alerta! de Jean Gremillion, Luis Candelas de Fernando Roldán y El rayo de José Buchs.

10 Hasta 1992 no se estrenará, recuperada por la Filmoteca de Zaragoza y montada por Ferrán Alberich. Véase ALBERICH, F.: Carne de Fieras. Madrid, Filmoteca Española, 1993.

11 La actriz principal de El genio Alegre, Rosita Díaz Gimeno, fue acusada por Fernando Fernández de Córdoba de republicana y de tener relaciones con Negrín, por lo que fue detenida. Después de ser canjeada, marchó a San Sebastián y de allí, tras un complicado periplo acabó en Nueva York, casándose con el hijo de Negrín. La película se terminó utilizando una doble que aparecía de espaldas. GUBERN, R.: Cine español en el exilio. Barcelona, Lumen, 1976. p. 22.

12 Como recompensa, los estudios CEA serán los más beneficiados por el gobierno durante el primer franquismo. Véase ELENA, A.: Romancero marroquí. El cine africanista durante la Guerra Civil. Madrid, Filmoteca Española, 2004.

${ }_{13}$ Sólo la población activa del sector terciario ascendía a 1.300.000 trabajadores. Véase SOTO CARMONA, A: El trabajo industrial en la España Contemporánea, 1874-1936. Madrid, Anthropos, 1989.

14 Creado el 14 de marzo de 1933 por una orden del Ministerio de Agricultura, Industria y Comercio, sus atribuciones resultaban muy extensas, yendo desde la reglamentación de las relaciones comerciales de la distribución y exhibición, protección jurídica de las empresas, medidas de fomento y cuotas de pan- 
Sin una política planificada ni unitaria, el gobierno se convirtió en una productora más, que tuvo que aceptar en los primeros meses del conflicto las iniciativas radicales promovidas por las organizaciones obreras, especialmente por los anarcosindicalistas, los dueños de las calles y de los cuarteles. La CNT (Confederación Nacional del Trabajo) y la FAI (Federación Anarquista Ibérica) fueron quienes encabezaron la producción cinematográfica, tanto por su cantidad como por su calidad. No le iban a la zaga los grupos marxistas afines a la III Internacional, como el Partido Comunista de España y el Partit Socialista Unificat de Catalunya -además de su sindicato, la UGT (Unión General de Trabajadores)—, las Juventudes Socialistas Unificadas, la productora Film Popular, el Socorro Rojo Internacional, la Alianza de Intelectuales Antifascistas para la Defensa de la Cultura y algunos cuerpos del Ejército con mandos comunistas. Todos ellos tenían que disputarse muy especialmente con el gobierno de la Generalitat de Catalunya- los jirones que restaban de los estudios, el material, los técnicos y los profesionales que unos meses antes conformaban la industria cinematográfica nacional.

Por el contrario, en la zona franquista sólo se contaba con un grupo electrógeno y un equipo de iluminación que se utilizaría en los pequeños estudios sevillanos de CIFESA. Ante tal panorama, se optó por la producción en el extranjero. Así, los franquistas no apostaron por la lucha ideológica apoyada en el cine del mismo modo que los republicanos. Hasta abril de 1938 no se creará el Departamento Nacional de Cinematografía.

Entre julio de 1936 y abril de 1939 la producción de películas alcanzará un total de 592 títulos, sumados los documentales, noticiarios y filmes de ficción -incluidos los 15 largometrajes comerciales arriba indicados-, rodados por los dos bandos y los extranjeros que apoyaban a uno $u$ otro. Todos ellos se ocuparon de entretener, educar y mostrar al resto del mundo lo que ocurría en España, tal y como recoge en su magnífica recopilación Alfonso del Amo ${ }^{15}$ (Tabla 2).

Tabla 2. Producción de películas entre julio de 1936 y abril de 1939

\begin{tabular}{|c|c|c|}
\hline Años & Republicanas & Franquistas \\
\hline 1936 & 66 & 11 \\
\hline 1937 & 210 & 25 \\
\hline 1938 & 80 & 22 \\
\hline 1939 & 4 & 35 \\
\hline Total & 360 & 93 \\
\hline Extranjeras & 66 & 43 \\
\hline TOTAL & 426 & 136 \\
\hline
\end{tabular}

talla, regulación lingüística, aspectos fiscales, arancelarios, hasta aspectos industriales, turísticos, culturales, sanitarios o educativos. Véase VALLÉS COPEIRO DEL VILLAR, A.: Historia de la política de fomento del cine español. Valencia, IVAC/La Filmoteca, 1992.

15 AMO, A.: Catálogo general del cine de la Guerra Civil. Madrid, Cátedra/Filmoteca Española, 1996. 


\subsection{La propuesta anarquista}

Para los cenetistas el cine iba mucho más allá del mero divertimento, era «el agente de propaganda más activo de la revolución proletaria, el reflejo más vivo de la nueva sociedad» ${ }^{16}$. Esta premisa se hallaba en la base de su febril producción, bastante más dilatada que la del resto de las organizaciones frentepopulistas. Durante 1930 en Barcelona, donde era la fuerza sindical mayoritaria, había constituido el SEUP (Sindicato Único de Espectáculos Públicos). Las propuestas de mejoras salariales y sociales de sus afiliados así como la reordenación de la industria cinematográfica, marcaron su actuación durante el conflicto.

Nada más estallar la guerra se creó su Oficina de Información y Propaganda en la ciudad condal que enseguida produjo el corto Reportaje del movimiento revolucionario en Barcelona dirigido por Mateo Santos. Las imágenes alborozadas de un violento anticlericalismo y el caos sembrado por los milicianos en su toma de la ciudad iban a recorrer el mundo. Estas primeras imágenes, junto a las rodadas por los múltiples e improvisados reporteros mostrando el aplastamiento fascista, serán pronto utilizadas por la contrapropaganda para denunciar los excesos turbulentos. Joaquín Reig —el primer director del noticiario franquista, el NO-DO-, montó en Berlín, durante abril de 1938, España heroica, tomando prestadas estas imágenes para dar respuesta con ellas a los filmes que la República mostraba ante el mundo, muy superiores a los producidos hasta ese momento por los franquistas ${ }^{17}$.

La producción de la CNT se organizó en cuatro apartados: reportajes de guerra y retaguardia, películas de propaganda, filmes de complemento para acompañar a los largometrajes y películas de ficción. Entre los primeros se hallan los avances bélicos alcanzados por Buenaventura Durruti en el frente de Aragón y películas de adoctrinamiento: Bajo el signo libertario (Ángel Lescarboure, 1936) que elogia las colectivizaciones en Aragón, En la brecha (Ramón Quadreny, 1937) o En el frente y la retaguardia (Joaquín Giner, 1937). Sin embargo, lo más complejo fue realizar películas de ficción, pues hacía falta algo más que llevar una cámara al hombro. Como, además, se pretendía cultivar un «cine social», el Comité de Producción puso en marcha guiones como Aurora de esperanza (Antonio Sau, 1937) donde un obrero en paro y su compañera tomaban conciencia social a lo largo de un proceso revolucionario. A éste le siguió Barrios bajos (Pedro Puche, 1937), un folletín sobre la lucha por la vida en los arrabales, y un mediometraje sobre la evolución revolucionaria de un niño rico ¡Nosotros somos así!

Al no obtener mucha aceptación por parte del público, se decidió volver al cine convencional para, al menos, recuperar la inversión. ¡No quiero, no quiero! película basada en una obra de Jacinto Benavente y dirigida por el filofascista pero buen

16 Tiempos nuevos, 1 de diciembre de 1936. Cit. en SALA NOGUER, R.: El cine de la España republicana durante la guerra civil. Bilbao, Mensajero, 1993. p. 47.

17 Véase SÁNCHEZ-BIOSCA, V.: Cine y Guerra Civil Española: del mito a la memoria. Madrid, Alianza, 2006, pp. 49-50. 
profesional Francisco Elías, se estrenaba cerca del final de la guerra. Para entonces, las luchas internas habían terminado con la fortaleza de la CNT, comenzadas tras la muerte de su líder, Durruti, en noviembre de 1936, a quien se le dedicará un apasionado reportaje: El entierro de Durruti.

Los postulados de la CNT habían ido mucho más allá de la simple producción. Además de socializar estudios y laboratorios, el sindicato incautó y sindicalizó las 116 salas barcelonesas, de donde extrajo el presupuesto para sus producciones. Pero los grandes descalabros económicos, seguidos de la intervención de la Generalitat en el sector de la exhibición y el ascenso del PSUC y de la UGT, acabaron con la apuesta cenetista.

En Madrid, donde la implantación anarquista era muy inferior, su producción también resultó más modesta. La compleja situación militar inspiró documentales como Fortificadores de Madrid (Antonio Polo, 1936), la serie Estampas de Madrid del francés Armand Guerra y el docudrama iAsí venceremos! (Fernando Roldán, 1937). Sólo un largometraje de ficción se produjo en la capital asediada, Nuestro culpable (Fernando Mignoni, 1937). Su desenlace amoral, en el que se dejaba en libertad a un delincuente, fue muy criticado.

La apasionada defensa de la revolución social, las experiencias libertarias y la lucha contra el fascismo recogidos en los filmes anarquistas, resultaron ser lo más relevante de su producción, sobre todo en contraposición con las posturas comunistas, para quienes el orden militar era el objetivo de absoluta prioridad.

\subsection{La aportación comunista}

Las tesis del mando único, a las que también se unieron socialistas y republicanos, así como la unidad en el poder, en los planteamientos económicos, políticos y sociales quedaron reflejadas en las producciones cinematográficas comunistas. Títulos como Por la unidad hacia la victoria, Ejército Popular o Mando Único de Fernando G. Mantilla iniciaron en 1937 la producción de la Cooperativa Obrera Cinematográfica ( $\mathrm{COC})$, que activó en Madrid una producción paralizada. Estos reportajes definían al enemigo como una fuerza extranjera invasora - fascistas y nazis-contra la que todos los españoles deberían combatir.

Mientras tanto, los múltiples grupos de filmación comunistas surgidos en Barcelona al inicio de la guerra fueron desapareciendo, debido a la tendencia hacia un cine único, un cine que aglutinara los esfuerzos volcados en las tareas de propaganda. La productora Film Popular será la voz y la imagen más sobresaliente del aparato cinematográfico comunista.

Su principal tarea fue la de elaborar el noticiario semanal España al día. Aunque en un principio se locutara en catalán, a partir del quinto número el gobierno de la Generalitat decidió editarlo en castellano para que fuera difundido por toda la $\mathrm{Pe}-$ 
nínsula. También se montó una versión en inglés y otra en francés. Parte de su producción se dedicó a mostrar la tranquilidad cotidiana o la sensibilidad cultural del bando republicano, a través de documentales sobre temas cívicos y didácticos como Tesoro Artístico (1937), La cerámica de Manises (1937), El telar (1938) o El tribunal de las aguas (1938) dirigidos por Ángel Villatoro. Se pretendía contrarrestar el descrédito urdido por la contrapropaganda fascista, que les tachaba de bárbaros, ignorantes y salvajes.

El resto de las organizaciones comunistas dedicaron gran parte de su actividad a relatar la vida en la retaguardia o el entusiasmo de las gentes, como en la serie La Defensa de Madrid, producida por la Alianza de Intelectuales Antifascistas y el Socorro Rojo Internacional, con la participación de las Brigadas Internacionales. Uno de los momentos culminantes de la cinta es el apasionado recital del poeta Rafael Alberti dedicado a la resistencia de la ciudad. Se pretendía inyectar de moral a las milicias combatientes, al reflejar las gestas bélicas que liberaban a la capital de la tenaza nacionalista. Asimismo subrayaba, de manera oficiosa gracias a la presencia de los brigadistas, cómo las democracias occidentales reconocían y apoyaban la lucha republicana.

Por último, los diferentes cuerpos del Ejército comunistas utilizaron sus secciones de propaganda, bien para adoctrinar a la tropa - El manejo de la ametraIladora (1936), El camarada fusil (1937) —, concienciar a la población civil —Soldados campesinos (1938) - o reclamar a las democracias extranjeras la necesaria ayuda que nunca llegaría — Frente a frente (1936)—.

Las producciones tanto de anarquistas como de comunistas, al menos en los primeros momentos, no gozaron de una gran calidad. En la mayoría de los casos, acusaban falta de guión y de ritmo, así como una deficiente fotografía hasta el punto de ser muchas de ellas improyectables. Se dilapidó la película virgen y se destrozó el material al ser manipulado por manos inexpertas.

\subsection{La apuesta gubernamental}

Llama la atención la infinidad de entidades que, desde el propio gobierno, se van a ocupar de la producción cinematográfica republicana. Ésta sufrirá desde el principio de la guerra los vaivenes institucionales ${ }^{18}$. En un primer momento estuvo adscrita a la Sección de Propaganda del Ministerio de Instrucción Pública y Bellas Artes pero, tras el traslado del gobierno a Valencia, en mayo de 1937, pasó a depender del Ministerio de Estado. La capital, bajo las órdenes de la Junta Delegada de Defensa, mantendrá su propia Comisión de Propaganda, a la que se unirá la producción de los diferentes ministerios, cuerpos del ejército, comités, comisariados, comandancias, escuelas militares... Todos y cada uno disponían de su propia

18 Véase SALA NOGUER, R.: Op. Cit., pp. 154-220. 

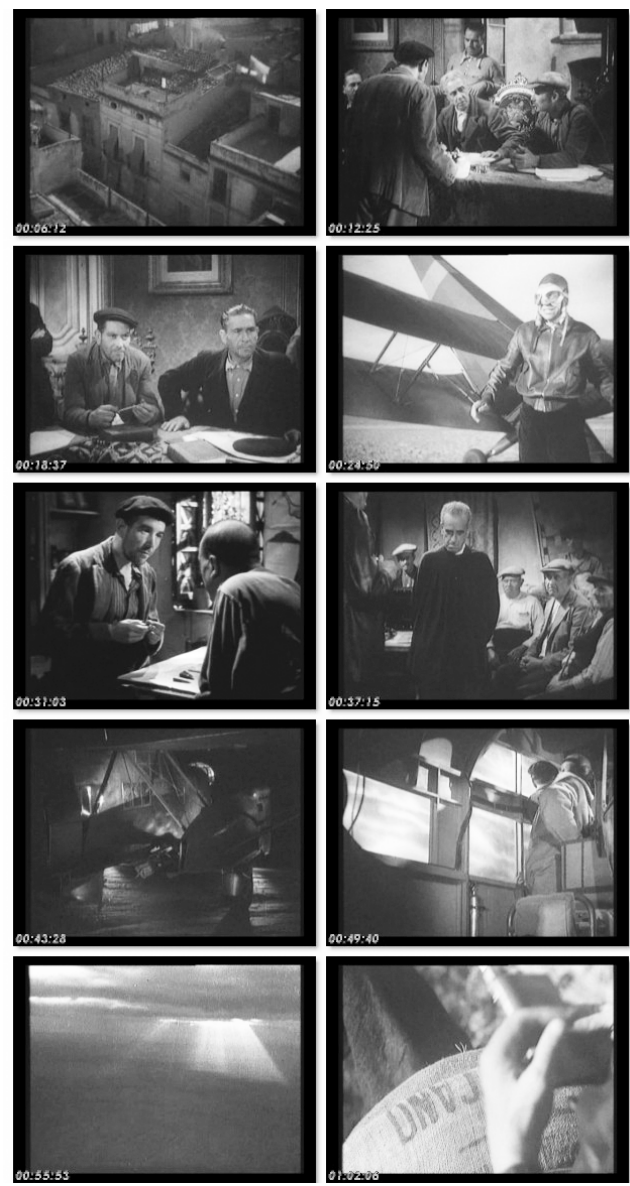

Fotogramas de Sierra de Teruel (André Malroux, 1939).

sección de cinematografía. Por otra parte, la frontera entre el aparato estatal republicano y los intereses comunistas resultaba bastante borrosa, incluso tras el pacto de mayo de 1937 (entre CNT-FAI, POUM y PCE-PSUC) y la salida de Indalecio Prieto del gobierno Negrín en abril de 1938, confundiéndose la propaganda de partido con la gubernamental ${ }^{19}$.

La realización más significativa de este primer periodo será el documental España 1936 (Jean Paul Le Chanois, 1937), también llamado España leal en armas, que busca en un público extranjero el apoyo a la legalidad republicana. Asimismo, el Gobierno financió la mítica Sierra de Teruel, dirigida por André Malroux

19 Un acercamiento general a la evolución del gobierno véase CASANOVA, J.: República y guerra civil. Barcelona, Crítica, 2007. Respecto a la postura de Negrín, MORADIELLOS, E.: Don Juan Negrín. Madrid, Península, 2006. 
y concluida en París en $1939^{20}$. En esta obra se habían puesto todas las esperanzas propagandísticas para romper el bloqueo de la No Intervención, tras los tremendos fracasos militares. El film muestra la generosa entrega de una escuadrilla de pilotos multinacional a la causa republicana. Su estética realista cercana a la épica del cine soviético alcanza el momento culminante al final de la cinta con la escena coral, intensa y emotiva, del descenso del pueblo por la montaña -en la que participaron 2.000 actores- acompañando los cuerpos de sus héroes.

\subsection{Otras instituciones}

Entre las otras muchas y variadas producciones, es destacable la propuesta del Comissariat de Propaganda de la Generalitat de Catalunya a través de Laya Film. Su primer documental fue Un día de guerra en el frente de Aragón (Joan Serra, 1936), seguido de más de dos centenares de títulos (casi uno cada tres días). Su objetivo era, una vez más, difundir en el exterior las razones de la causa republicana, lo mismo que el noticiario semanal España al día, del que se editaron 90 números. El reportaje más dramático editado será Catalunya mártir (Jaume Miravitlles, 1938). Locutado en varios idiomas denunciaba los bombardeos aéreos y la violación de la legalidad democrática.

Pero de nada sirvieron las películas, las fotos, los folletos, las embajadas o los discursos ante la ONU, el 1 de abril de 1939, 225 profesionales de la industria cinematográfica, entre los que se encontraban veintitrés directores, un $10 \%$ de los actores y una ingente sangría de operadores, guionistas, músicos, críticos, escenógrafos así como un elevado número de técnicos debieron iniciar un largo exilio que, en algunos casos, acabó con su muerte.

\section{EL MODELO FRANQUISTA}

En todos los ámbitos, la propaganda franquista estuvo muy por debajo de la republicana, de hecho su producción no alcanzó ni la cuarta parte, aunque el porcentaje varía si se incluyen las cintas realizadas en el extranjero (véase Tabla 2). En este bando se tardará bastante en organizar un sistema de información coherente, el cual comenzó en otoño de 1936 con dos reportajes: Con las brigadas navarras (Miguel Pereyta, 1936) y la Toma de Bilbao (Miguel Pereyta, 1937) realizados por Cine Requeté. La dirección de la Delegación del Estado para Prensa y

20 El rodaje se inició en los estudios Orfea de Barcelona en agosto de 1938. En febrero de 1939 el cerco a la ciudad obligó al equipo a trasladarse a los estudios de Joinville (París). Una vez finalizada, en julio y agosto de 1939 se proyectó de manera privada en París ante Negrín y algunos ministros republicanos en el exilio. El estreno oficial en Francia se efectuó en abril de 1945. Hasta el 26 de julio de 1978 no se estrenará en Madrid. AUB, M.: «André Malraux et le cinéma». Archivos de la Filmoteca, 3, (1989), pp, 56-59. 
Propaganda de Falange (DEPP) le fue encomendada al escritor Dionisio Ridruejo. Al no disponer ni de material ni apenas técnicos, obtuvo un escaso éxito. Hasta el 1 de abril de 1938 no se creará el Departamento Nacional de Cinematografía, dirigido por Manuel Augusto García Viñolas. Los servicios técnicos estaban a cargo de José Luis Sáenz de Heredia.

La falta de medios obligó a concentrar en un solo organismo la producción cinematográfica y convertir en esencial la ayuda italiana y alemana. Desde un principio el material rodado se envió a los laboratorios de la Tobis en Berlín. Alberto Reig montó allí el ejemplo más significativo de exaltación retórica, la citada España heroica, que manipula la emotividad para justificar la sublevación. Mitos como la Reconquista y la Cruzada estaban presentes en esta obra que, a partir de entonces será un constante leitmotiv en la propaganda franquista. A diferencia de la pluralidad republicana, un maniqueo y monolítico discurso insistía de manera machacona en la salvación de España del peligro rojo, gracias al orden aportado por la sumisión al poder militar, lo que se reflejaba en el gusto por los múltiples desfiles y su organización geométrica, cuadriculada.

La imposibilidad de rodar películas de ficción se soslayó gracias a la firma hispano-germana Hispano-Film-Production (vinculada a CIFESA, con la colaboración de Saturnino Ulargui), que produjo cinco cintas de corte netamente español: dos realizadas por Florián Rey, Carmen la de Triana (1938), una de sus mejores realizaciones, seguida de la fallida La canción de Aixa (1938). Ambas estaban interpretadas por su mujer, Imperio Argentina. Benito Perojo fue el director de las otras tres: El barbero de Sevilla (1938), Suspiros de España (1938) —la más comercial de todas - y Mariquilla Terremoto (1939), protagonizadas por Estrellita Castro.

Por otra parte, en octubre de 1938 Dionisio Ridruejo se entrevistaba en Roma con Dino Alfieri, ministro italiano de Cultura Popular. Ambos dirigentes acordaron la realización de dos películas: Santa Rogelia y Frente de Madrid, dirigidas por Edgar Neville. Fruto de este encuentro también Perojo podrá rodar Los hijos de la noche (1939), coproducción financiada por Saturnino Ulargui y la Imperator italiana, que no gustaría ni a fascistas ni a falangistas por su final en el que un republicano y un nacionalista se reconcilian en el hueco de un obús, escena suprimida por la censura.

\subsection{La censura}

Quizá éste sea el peor legado cultural que ha dejado el régimen franquista, aunque la censura cinematográfica no nacería ni 1 de abril de 1939 ni el 18 de julio de 1936, puesto que las primeras normas censoras se dictaron en España en 1913. A lo largo del siglo XX se irán imponiendo en todos los países.

Durante la Segunda República se mantuvo en vigor una real orden dictada el 12 de abril de 1930 por la que la Dirección General de Seguridad asumía las 
competencias examinadoras sobre todas las obras exhibidas. Como la mayor parte de las empresas distribuidoras se hallaban en Barcelona y aquella se encontraba en Madrid, ante las protestas catalanas, el gobierno decidió atomizar sus competencias y entregárselas a los gobiernos civiles. Al encontrarse este poder más próximo a las autoridades locales, además de estar sometido a la presión de las ligas y asociaciones que pugnaban por una mayor moralidad, se produjo una mayor sensibilidad censora. Los católicos y la Asociación Nacional de Padres de Familia fueron especialmente combativos en este aspecto. Su boletín semanal, Filmor, servía de guía a las asociaciones católicas para elaborar su particular lista censora. Su publicación en la prensa conservadora facilitó una difusión nada desdeñable.

Pero como la censura de la posterior institución franquista, ninguna. La encargada de su organización será la DEPP, quien crea la Junta Superior de Censura Cinematográfica el 19 de noviembre de 1937 por orden del Ministerio de Interior. En ella confluirán los intereses de los católicos y del gobierno de Burgos. A partir de este momento el aparato censor quedó unificado; anuló las atribuciones del Gabinete de la Coruña ${ }^{21}$ y asumió las de las jefaturas provinciales - bajo católicos y falangistas-y las de los mandos militares, quienes hasta entonces habían podido decidir sobre los contenidos de los medios de comunicación. Siguiendo el modelo italiano, la Junta sólo tuvo dos secciones: una en Sevilla, encargada de censurar el cine de ficción y otra en Salamanca, mucho más cerca del poder, para los documentales y noticiarios ${ }^{22}$. A partir de este momento la censura dejó de ser un proceso de urgencia, localista y contrarrevolucionario para convertirse en un ente oficial, centralizado e incorporado a las funciones propagandísticas asignadas a Falange, bajo la mirada omnisciente de su jefe máximo, Ramón Serrano Suñer. Desde el 10 de diciembre de 1938 la censura cinematográfica, dependiente del Ministerio de Gobernación, tuvo su propia normativa que regulaba todo lo referido a la producción y exhibición de los ya pronto vencedores de la guerra ${ }^{23}$.

\section{4. ¿QUÉ SE VEÍA EL CINE?}

Las mejoras sociales conseguidas en el primer cuarto del siglo $\mathrm{XX}$, entre ellas la reducción de la jornada laboral y un ligero incremento de los salarios, habían permitido un aumento del tiempo del ocio, empleado por muchos en asistir al cine. En 1935 la población española ascendía a 24.693.000 habitantes. Para ellos existía un parque cinematográfico compuesto por 2.767 salas, de las cuales 1.533

21 Había sido creada junto al Gabinete de Censura Cinematográfico de Sevilla el 21 de marzo de 1937 por una Orden del Gobierno General. GUBERN, R. y FONT, D.: Un cine para el cadalso. Barcelona, Euros, 1975, p. 17.

${ }_{22}$ Véase DÍAZ PUERTAS, E.: El montaje del franquismo. La política cinematográfica de las fuerzas sublevadas. Barcelona, Alertas, 2002, pp, 121-142.

${ }^{23}$ GUBERN, R. y FONT, D.: Op. Cit, pp. 21-23. 
eran sonoras y 1.234 aún mudas. El aforo total ascendía a 1.504.09124. Después de Estados Unidos, España era el país del mundo con mayor número de butacas por habitante.

La exigua producción nacional no era suficiente para abastecer a tantos locales, por lo que las películas norteamericanas, francesas y alemanas copaban las pantallas. En 1934 y 1935 se importaron un total de 474 y 454 películas respectivamente. De ellas, el $73 \%$ y $74 \%$ vinieron de Estados Unidos, de Francia el $13 \%$ y el $8 \%$ y de Alemania el $9 \%$ y el $10 \%$ cada año ${ }^{25}$. Estas cintas, además de las de producción nacional del periodo bélico, las escasas importaciones rusas ${ }^{26}$, y las alemanas y norteamericanas que lograron desembarcar y atravesar las líneas de fuego - sin alcanzar ni la mitad que durante los años anteriores-, fueron las que se proyectaron una y otra vez en los cines de ambas zonas durante la contienda. Ir al cine era uno de los pocos signos de normalidad entre tanto horror.

Los espectadores eran ajenos a los ajetreos del negocio cinematográfico. No les importaba ni la incautación o socialización de las salas, ni el corte de suministro de películas, ni la huída de distribuidoras internacionales, ni la machacona repetición de las mismas cintas...., sólo querían refugiarse en su butaca y disfrutar de un par de horas de evasión.

Y la evasión preferida se encontraba en las comedias, lo castizo, los musicales - desde operetas alemanas al vodevil norteamericano de «Ginger (Rogers) y Fred (Astaire)"一, las películas de aventuras, de terror y de acción. Nada de truculentos melodramas - a no ser que fueran acompañados de grandes movimientos de masas, al estilo Cecil B. De Mille (El signo de la Cruz, 1932; Cleopatra, 1934; Las cruzadas,1935). En una palabra, el cine de género que comienza a configurarse en el Hollywood de entreguerras y que triunfará en todo el mundo27. Por supuesto, ni críticos ni intelectuales coincidían en los gustos del gran público, situación que no ha variado setenta años después, aunque con sus matices.

Lo primero que afectó a la exhibición cinematográfica fue la incautación o socialización de las salas. En Barcelona, sus 116 salas pasaron a manos de los empleados, la mayoría afiliados al Sindicato Único de Espectáculos Públicos de la CNT. Desparecido el empresario, la euforia llevó a los obreros a redactar un estatuto que regiría la colectivización de los locales, reglamento dado a conocer el 8 de agosto de 1936. En su artículo 22, se hacía referencia al Comité Económico que se

24 VALERO DE BERNABÉ, A.: España cinematográfica. Madrid, Cinégrafos, 1943 y Anuario Cinematográfico Español. Madrid, R. de Rodrigo, 1935.

${ }_{25}$ Cifras extraídas de la Estadística del Comercio Exterior. Madrid, Ministerio de Hacienda. Dirección General de Aduanas. Anuarios de 1934, 1935 y junio de 1936.

26 En Madrid apenas ocuparon un 3,7\% de la cartelera durante toda la guerra, aunque entre el 10 de noviembre y el 22 de diciembre de 1936 en la capital sólo se vió cine soviético. A partir de esa fecha regresaron las producciones de todos los países. CABEZA SAN DEOGRACIAS, J.: El descanso del guerrero: cine en Madrid durante la guerra civil española (1936-1939). Madrid, Rialp, 2005, p. 17.

${ }_{27}$ Véase PAZ, M. ${ }^{a}$ A. y MONTERO, J.: El cine informativo, 1935-1945. Barcelona, Ariel Comunicación, 1999. 
ocupará de la recaudación en cada sala para pagar a los distribuidores, comprar el nuevo material y la inversión en la producción destinada a la CNT. También se igualaron los salarios en todas las categorías laborales y los beneficios de taquilla se distribuyeron entre los empleados a porcentaje según el trabajo realizado. Como en el resto de la zona republicana, nadie aplicó el apartado del artículo 22 relativo a la necesidad de pagar los alquileres de las salas y películas, ni a los distribuidores locales o a las compañías productoras internacionales. Se trataba de una muestra más de la lucha contra la propiedad privada, cuestión de principios que enfrentaba la economía colectivista a la de libre mercado.

En Madrid la correlación de fuerzas era mayor y los cines colectivizados de la capital se repartieron entre CNT y UGT, según la adscripción de los trabajadores que, de manera separada o conjuntamente, gobernaban todas las salas. De las 190 salas que funcionaron intermitentemente durante la guerra, sólo un $32 \%$ fueron administradas por la UGT ${ }^{28}$. A pesar del caos inicial, en ningún momento disminuyó la asistencia del público. No se detenían las proyecciones ni siquiera por los bombardeos. El entusiasmo desbordante confundió la incautación de los locales con su uso ad libitum para todo tipo de actos benéficos, experiencias renovadoras o entrega de recaudaciones, actos llevados a cabo con la ingenuidad y espontaneidad de quienes querían cambiar las cosas pero sin saber cómo hacerlo. En cualquier barrio y local de Madrid se hacían funciones únicas -el toque de queda impedía los pases nocturnos- para recaudar fondos y explotar las películas rodadas en el frente. Fue entonces cuando el gobierno puso en circulación las películas relativas a la revolución soviética de 1917. Los marineros de Cronstadt (lefim Dzigan, 1936), Octubre (Sergei M. Eisenstein, 1928) o Tchapaev (Georgi y Serguei Vassiliev, 1934) Ilenaron las pantallas de la Gran Vía e insuflaron fervor revolucionario a una población asediada y abandonada a su suerte.

A partir del 31 de enero de 1937 el caos se normalizó con la creación de la Junta de Espectáculos, presidida por el republicano José Carreño, que asumió las funciones de censura, administración y ordenación artística de la capital. La Junta exigió un traspaso de competencias que los comités obreros no estuvieron dispuestas a cumplir. La mayoría de los cines abiertos reponían tanto las películas norteamericanas que quedaban en la capital como las españolas «contrarrevolucionarias». Una y otra vez desde la prensa se insistía en «cambiar el mal gusto del público", con criticas similares a las lanzadas contra el anterior Comité Económico de Cines. En diciembre de 1937 Juan Negrín constituyó una nueva Junta, la cual tampoco tuvo el apoyo de UGT. La disyuntiva siempre era la misma: o se apostaba por películas y espectáculos de calidad que mejoraran el nivel cultural de los espectadores, con el riesgo de la desertización de las salas o se programaban las películas sin «elevación artística» ni combatividad que agradaban más al público.

28 CABEZA SAN DEOGRACIAS, J.: Op. Cit, pp. 20-25. La media por semana era de 35 cines abiertos. 
Una polémica que se mantuvo hasta el final de la guerra. En realidad, el $60,8 \%$ de las películas de ficción que se proyectaban fueron norteamericanas, el $13,25 \%$, españolas; un 7,5\%, francesas; un 4,9\% alemanas y un $4,5 \%$, inglesas ${ }^{29}$.

En Valencia, el 19 de julio de 1936 se hallaban salas desiertas al seguir la huelga general decretada por la CNT y UGT. Hasta el 5 de agosto permanecieron los cines cerrados. Al igual que en el resto de ciudades, los dos sindicatos se unieron para crear el Comité Ejecutivo de Espectáculos Públicos que facilitaría la puesta en marcha de medidas tendentes a la socialización. No faltaron los filmes soviéticos ni los festivales cinematográficos con el fin de recaudar fondos para la guerra, con las consiguientes polémicas sobre concienciación o taquilla. Una vez más se hicieron patentes las contradicciones entre llenar las salas con Morena Clara y Nobleza baturra —de nuevo las más taquilleras-y las «frivolidades de Hollywood» o influir desde la pantalla en la conciencia bélica y acercarse a las necesidades del proletariado.

En general, la consecuencia de tanta desorganización en la zona republicana fue la escasez de estrenos para la temporada 1937-38. El retraso en la liquidación de deudas a distribuidores internacionales - había que pagar con unas divisas necesarias para otros menesteres-, el aumento de salarios del personal de las filiales extranjeras en España, el descenso de los alquileres de las películas y la obligatoria contribución a las necesidades de guerra, volvieron al mercado español insostenible. Los norteamericanos abandonaron España, no obstante continuaron negociando desde París con ambos gobiernos, aunque de diferentes formas. Columbia, Warner e Hispano American abrieron una línea de crédito al gobierno republicano, permitiendo el ingreso de las recaudaciones en operaciones poco transparentes (divisas compradas en el mercado negro) o en pesetas ${ }^{30}$. La Paramount se alineó con la causa republicana en sus noticiarios criticando al bando franquista. Por el contrario, la MGM y la 20th Fox hicieron de sus informativos la voz de los nacionalistas en Estados Unidos. La Fox incluso envió un equipo de reporteros, gesto que resultó bien recompensado: del centenar de licencias de importación concedidas durante la guerra por los franquistas, más de la mitad fueron para la $F_{o X^{31}}$. Sus pagos tampoco fueron del todo trasparentes... la guerra fue considerada como situación extraordinaria.

El posicionamiento de las majors no interfirió en que un $20 \%$ de las proyecciones hollywoodienses del Madrid republicano fueran de la MGM, seguidas del $11 \%$ de la Fox, aunque las críticas a las programaciones cinematográficas le llovieron al gobierno republicano desde los rotativos. Hora de España, Claridad, El

29 Ídem, p. 39.

30 Sobre las relaciones con Estados Unidos, véase LEÓN DE AGUINAGA, P.: El cine norteamericano y la España franquista, 1939-1960: Relaciones internacionales, comercio y propaganda. Tesis doctoral, p. 61. http://eprints.ucm.es/8378/1/T30698.pdf.

31 Archivo General de la Administración (AGA), Cultura. Caja 21/1. «Relación de películas importadas después del 18 de julio de 1936», s.f. 


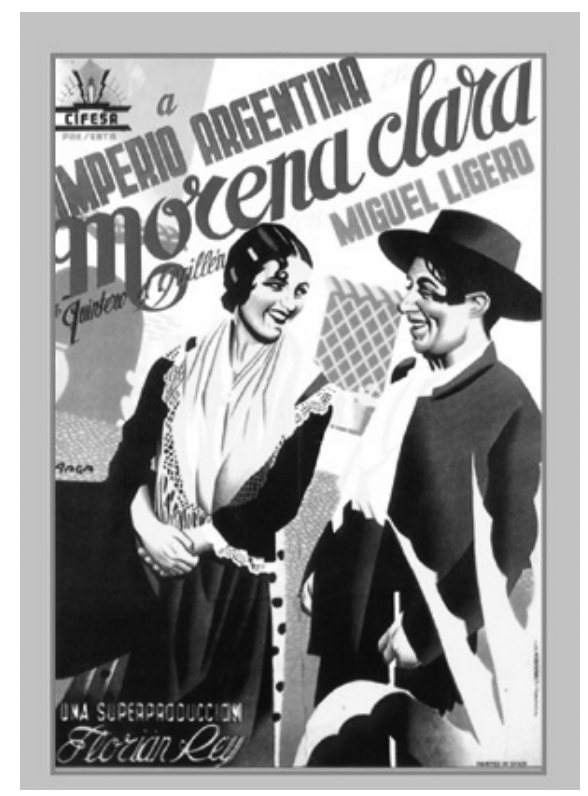

Cartel de Morena Clara (Florian Rey, 1936).

Sol o Mundo obrero demandaban una censura política que impidiera la proyección de películas burguesas y contrarrevolucionarias de notable «intrascendencia» y representantes de «todo lo viejo y lo podrido» ${ }^{32}$. Rebelión a bordo, Historia de dos ciudades, o las españolas Diego Corrientes, Luis Candelas, La canción del día y Rinconcito madrileño sufrieron las arremetidas de la prensa intelectual, comunista y socialista. De ahí la necesidad de producir un cine social alejado de planteamientos burgueses.

Pero las cintas preferidas del público seguían siendo las comedias españolas con números musicales. Las veinticinco películas más taquilleras del periodo fueron españolas. Destacan Morena Clara (Florián Rey, 1936), Nobleza baturra (Florián Rey, 1935), La verbena de la Paloma (Benito Perojo, 1935) y Carmen la de Triana (Florián Rey, 1936). Entre las extranjeras triunfaron El congreso se divierte (Jean Boyer y Eric Charell, 1931), Una noche en la ópera (Sam Wood, 1935), El signo de la cruz (Cecil B. De Mille, 1932) y Los mares de China (Tay Garnett, 1935).

Aún así, a pesar de la enorme presencia del cine norteamericano, de los esfuerzos del gobierno republicano por mostrar el cine soviético y de las dificultades de los nacionalistas para importar, el $20 \%$ de las películas más taquilleras fueron las españolas, unidas a las rodadas en Alemania o en Hollywood por artistas es-

${ }^{32}$ SALA NOGUER, R.: Op. Cit., p. 274. 
pañoles ${ }^{33}$. Por aquel entonces, una tercera parte la población era analfabeta y, en cierto modo, esta elevada tasa influía en el éxito comercial de las películas españolas sobre las extranjeras, que se proyectaban subtituladas. Resultaba más agradable una trama cercana y sencilla, con canciones conocidas y de factura mediocre, que una película foránea de mayor calidad pero con un lenguaje cinematográfico mucho más complejo e incomprensible. Tampoco se debe olvidar que era mucho más fácil y barato explotar el material producido en España que el importado, puesto que las copias no tenían que cruzar fronteras y aduanas en pie de guerra y que el precio de su alquiler era inferior.

\section{EL FINAL DE LA GUERRA: LA GESTIÓN DEL NUEVO ESTADO}

La caída de Barcelona el 26 de enero de 1939 dio paso a la mayor ofensiva propagandística por parte de las tropas nacionales. Su primera tarea fue reordenar la exhibición aunque según una orden del 16 de febrero de 1937, ya se otorgaba a los mandos militares la potestad de incautar los bienes pertenecientes a sindicatos y asociaciones y así lo habían hecho a la vez que avanzaban por el territorio español.

A la ciudad condal se llevaron ingenieros para poner en funcionamiento los proyectores y reparar las cabinas, se facilitaron repuestos - carbones, cruces de Malta, lámparas, altavoces-, se contrataron proyeccionistas, acomodadores y se imprimieron billetes para las entradas. El 30 de enero se reabrieron las salas sólo con proyecciones del Departamento Nacional de Cinematografía (DNC): 18 de Julio, La Ciudad Universitaria, Juventudes de España, Prisioneros de guerra... Dionisio Riduejo, brazo en alto, presidió la reentré en el Astoria. Un equipo de rodaje dirigido por Edgar Neville se ocupó de filmar la conquista de la ciudad, que será exhibida inmediatamente. Durante los tres primeros días la entrada en los cines fue gratuita; después se pasó a cobrar una peseta. Orden y patriotismo iban a ser las consignas de la DNC: unas diapositivas de Franco al principio de cada sesión obligaban al saludo con el brazo en alto ${ }^{34}$. El 1 de febrero, la compañía ClFESA se sumaba a la campaña de propaganda presentando los documentales que había ido rodando según avanzaban las tropas: Asturias para España (1937), España heroica (1938), Reconstruyendo España (1937-1938), Homenaje a las brigadas navarras (1937) y Salamaca $(1938)^{35}$.

Entretanto en Madrid, las discrepancias entre comunistas - que deseaban resistir- y casadistas —que llevaban negociando la rendición desde hacía me-

33 CAÑADA ZARRANZ, A.: El cine en Pamplona durante la Il República y la Guerra Civil (1931-1939). Pamplona, Gobierno de Navarra, 2005. Los datos que aporta resultan muy significativos pues están elaborados sobre las agendas de programación y recaudaciones de los tres cines principales de la ciudad.

34 AGA. Cultura, caja 273, 4 de marzo de 1939. De este modo se sentó a quienes se levantaban a cada nota militar de los documentales proyectados y se levantó a quienes no se movían del asiento.

35 DÍAZ, E.: «Guerra civil y cine: la ocupación cinematográfica de Barcelona y Madrid». Secuencias, 6, (1997), pp. 28-30. 
ses- provocaron, entre otras cosas, la paralización de los cines desde el 7 al 14 de marzo de 1939. Finalmente, tras la derrota de los comunistas, desaparece la propaganda de las salas y éstas son tomadas por quintacolumnistas. Un equipo de filmación formado por Rafael Gil, Eusebio Fernández Ardavín, Julián de la Flor y Daniel Quiterio Prieto rodó el 28 de marzo las primeras imágenes de la liberación de la ciudad ${ }^{36}$. Ya llevaban días filmando para ofrecer a los vencedores secuencias sobre la realidad última de un Madrid sitiado: hambre, frío, miseria y desolación.

El mismo 1 de abril comenzaría la campaña de proyección de películas: doce salas, entre ellas el Proyecciones con Jimeno a la cabeza, conformaron este circuito. El sábado siguiente, Sábado de Gloria, Julián Casanova puso en marcha su propio plan de ocupación para hacerse con siete cines madrileños. En el cine Capitol se estrenaba La liberación de Madrid (1939) montada en los laboratorios Madrid Film. Enrique Blanco regresaba a sus quehaceres, aunque por poco tiempo. Su pertenencia a la masonería no tendría perdón.

Ese mismo día, Estados Unidos, después de Francia y Gran Bretaña, reconocía el régimen de Franco.

\section{CONCLUSIONES}

El conflicto bélico vino a truncar los avances que la producción cinematográfica española había iniciado tras la revolución del sonoro. La puesta en marcha de estudios sonoros en Madrid y Barcelona había ampliado la producción de cintas, que en el verano de 1936 había alcanzado la cifra de once largometrajes de ficción.

Las productoras de los años veinte prácticamente habían desaparecido, invirtiendo en este sector las distribuidoras que se habían hecho con la industria. Las mayores empresas con las características de una industria moderna fueron dos: la valenciana CIFESA y la madrileña Filmófono. Ambas sufrieron una tremenda transformación a causa del conflicto bélico, la primera salió fortalecida tras apoyar a los rebeldes, mientras que Filmófono sucumbió por la diáspora de sus cuadros técnicos debida a sus ideas republicanas.

Al iniciarse el conflicto, las productoras se socializaron o colectivizaron, desapareciendo la figura del productor e igualándose funciones y salarios. La huida de directores profesionales dejó en manos inexpertas la producción por lo que se dilapidó el capital existente invertido en película virgen y aparatos.

Fueron los partidos políticos y la administración quienes se hicieron cargo de la producción, intentando utilizar el cine como medio para educar y dirigir mensajes al público y la sociedad. El gobierno republicano se vio superado por las políticas de

${ }^{36}$ FERNÁNDEZ CUENCA, C.: Op. Cit, p. 668. 
los partidos, los sindicatos o las administraciones autonómicas, muchas veces enfrentadas entre sí e incluso contrarias a las directrices del gobierno central.

La producción de uno y otro bando nacional y extranjera dirigida a convencer a propios y extraños, conquistar, educar y distraer fue cuantiosa. Durante estos años se filmaron cerca de 600 títulos entre documentales y filmes de ficción tanto españoles como extranjeros referidos al conflicto. La proporción resultó bastante desigual, sólo una cuarta parte fue la realizada por el bando rebelde, al quedar los medios de producción en la zona republicana. Pero los contactos de los empresarios - sumados a la causa franquista - con otros países con regímenes fascistas, permitieron la filmación en el exterior de películas destinadas a su proyección en la zona de los sublevados, acercando su producción a la republicana.

Las salas de cine también fueron incautadas y comités obreros se ocuparon de regentarlas, distribuyendo los beneficios entre plantillas cada vez más abultadas. Los beneficios se repartían entre los sindicatos y partidos sin entregarse a los arrendatarios sus cuotas, por lo que resultó difícil contratar nuevas cintas durante el periodo bélico. Las distribuidoras extranjeras huyeron, aunque normalmente desde París seguían controlando el negocio, que funcionaba de igual manera con ambos bandos.

Más allá de los problemas del sector, el público lo que deseaba era evadirse a través de las películas, por lo que la mayor recaudación fue para las películas comerciales españolas y las norteamericanas de género. Las posturas críticas de intelectuales y periodistas en contra del gobierno por aceptar las películas «fascistas» estaban muy alejadas de los intereses del gran público y, por ende, de la taquilla.

El triunfo de los franquistas supuso la vuelta de la mayor parte de los productores y dueños de estudios así como de los directores y estrellas más taquilleras, quienes siguieron triunfando en los años siguientes. Aquellos más concienciados y comprometidos políticamente tuvieron que salir de España para, en muchos casos, no regresar jamás. El cine siguió siendo la única ventana amable para asomarse más allá de la miseria de una dolorosa guerra y una triste posguerra, aunque encuadrada por una férrea y monolítica censura nacida junto al pensamiento único.

\section{BIBLIOGRAFÍA}

ALBERICH, F.: Carne de Fieras. Madrid, Filmoteca Española, 1993.

AMO A.: Catálogo general del cine de la Guerra Civil. Madrid, Cátedra/Filmoteca Española, 1996.

ANUARIO Cinematográfico Español. Madrid, R. de Rodrigo, 1935.

CASANOVA, J.: República y guerra civil. Barcelona, Crítica, 2007.

CAÑADA ZARRANZ, A.: El cine en Pamplona durante la ll República y la Guerra Civil (1931-1939). Pamplona, Gobierno de Navarra, 2005.

CAPARRÓS LERA, J. M.: Arte y política en el Cine de la República, 1931-1939. Barcelona, Universidad de Barcelona, 1981. 
- El cine español bajo el régimen de Franco, 1936-1975. Barcelona, Universidad de Barcelona, 1983.

CELA, J.: La empresa cinematográfica Española Filmófono, 1929-1936. Madrid, Universidad Complutense, 1995.

DÍAZ PUERTAS, E.: El montaje del franquismo. La política cinematográfica de las fuerzas sublevadas. Barcelona, Alertas, 2002.

ELENA, A.: Romancero marroquí. El cine africanista durante la Guerra Civil. Madrid, Filmoteca Española, 2004.

FANÉS, F.: Cifesa, la antorcha de los éxitos. Valencia. Institución Alfonso el Magnánimo, 1981.

FERNÁNDEZ CUENCA, C.: La Guerra de España y el cine. Madrid, Filmoteca Nacional de España, 1976.

GUBERN, R.: Cine español en el exilio. Barcelona, Lumen, 1976.

- Historia del cine español. Madrid, Cátedra, 1995.

GUBERN, R. y FONT, D.: Un cine para el cadalso. Barcelona, Euros, 1975.

MORADIELLOS, E. Don Juan Negrín. Madrid, Península, 2006.

PAZ, M. ${ }^{a}$ A. y MONTERO, J.: El cine informativo, 1935-1945. Barcelona, Ariel Comunicación, 1999.

RIAMBAU, E. y TORREIRO, C.: Productores en el cine español. Estado, dependencias y mercado. Madrid, Cátedra/Filmoteca Española, 2008. p. 828.

SALA NOGUER, R.: El cine de la España republicana durante la guerra civil. Bilbao, Mensajero, 1993.

SÁNCHEZ-BIOSCA, V.: Cine y Guerra Civil Española: del mito a la memoria. Madrid, Alianza, 2006.

VALERO DE BERNABÉ, A.: España cinematográfica. Madrid, Cinégrafos, 1943.

VALLÉS COPEIRO DEL VILLAR, A.: Historia de la política de fomento del cine español. Valencia, IVAC/La Filmoteca, 1992.

VIZCAINO CASAS, F.: Historia y anécdota del cine español. Madrid, Adra, 1976.

VVAA.: Historia del Cine Español. Madrid, Cátedra, 1995. 